\title{
Examining the Effect of Education on Dietary Calcium Intake in Reducing Blood Pressure Variability Among Pregnant Mothers in Tigray Region, Northern Ethiopia, Two Arm, Randomized Control Trail Parallel Design
}

Mulugeta Woldu Abrha ( $\nabla$ mulugetawoldu425@gmail.com )

Tigray Health Research InstituteTigray Health Research Institute, Mekelle, Ethiopia https://orcid.org/0000-0001-7990-8940

Alemnesh Abarha

Tigray Health Research Institute

Ataklty Gebretsadik

Tigray Health Research Institute

Brhane Ayele

Tigray Health Research Institute

Haylay Gebretensae

Tigray Health Research Institute

Equbay Gebreegziabher

Tigray Health Research Institute

Tsegay Hadgu

Tigray Health Research Institute

Afework Mulugeta

Mekelle University College of Health Sciences

\section{Research}

Keywords: Calcium, education, pregnant mother, blood pressure variability, Ethiopia

Posted Date: September 14th, 2020

DOI: https://doi.org/10.21203/rs.3.rs-71446/v1

License: (c) (1) This work is licensed under a Creative Commons Attribution 4.0 International License.

Read Full License 


\section{Abstract}

Background: Investigating effects of calcium diets on blood pressure can contribute to development of diet based recommendations for health. Epidemiologic data suggest contradicting evidence relationship between dietary calcium intake and pregnancy-induced hypertension. So, this study aimed to determine the effect of calcium nutrition education on blood pressure variability among pregnant mother.

Method: Single center, two-arm, main individual randomized trial parallel design; single blinded was conducted among 415 pregnant mothers. Bi-variable tabulations were computed to identify the distributions of the outcome variables by selected background characteristics. We estimated a multilevel model that assessed the relation of individual and community level factors (fixed effects) as well as community level random effects. All analysis was conducted using STATA 14 software.

Result: Blood pressure variability during pregnancy after 28 gestational age was significantly associated with weekly calcium nutrition education [AOR $=0.38 ; 95 \% \mathrm{Cl}: 0.19,0.5]$, pregnant mothers who attained secondary school [AOR=0.21, 95\% Cl: 0.20, 0.70], employed pregnant women [AOR=9.05; 95\% Cl: 1.95 , 14.02] , Antenatal Care [AOR=1.82; 95\% Cl: 1.01, 2.22], supplemented iron/folic acid [AOR=6.32; $95 \% \mathrm{Cl}$ : $1.09,36.59]$, food craving [AOR=0.78; $95 \% \mathrm{Cl}: 0.20,0.98]$, reading newspaper [AOR=9.05; $95 \% \mathrm{Cl}: 1.95$, 14.02], place of residence [AOR=2.11; $95 \% \mathrm{Cl}: 1.36,3.26]$.

Conclusion: Individual level factors (Calcium nutrition education, maternal educational status, maternal occupation, Antenatal care during last pregnancy and current pregnancy, iron/folic acid supplementation, food craving, dietary calcium level and reading newspaper) and community level factors (place of residence) were significant predictors of blood pressure variability. During antenatal visits, pregnant women should be made aware of some dietary practices which are harmful during pregnancy, and increase education regarding the benefit of adequate nutrition.

Trail Registration: PACTR, PACTR202009693949631 and Registered 02 September 2020- Retrospectively registered

\section{Background}

Calcium is the most abundant mineral in the body and essential for bone formation, muscle contraction, enzyme and hormone functioning, most of the body's calcium found in bone [1, 2]. Calcium has potential to reduce adverse gestational outcomes by decreasing the risk of developing hypertensive disorders during pregnancy, which are associated with a significant number of maternal deaths and considerable risk of preterm birth $[3,4]$.

Globally Over half a million women die each year from pregnancy related causes. Pregnancy related hypertensions are the second leading cause of maternal death; it accounts $27.1 \%$ of maternal death [5]. In Low and middle income countries maternal death accounts $99 \%$ of the total death at global level and 
about one out of every 10 maternal deaths in Africa and Asia have been attributed to pre eclampsia and eclampsia [6].

WHO recommended Calcium supplementation during early pregnancy for population with poor dietary calcium intake to prevent pregnancy related hypertension [2, 4]. In Ethiopia dietary calcium intake is too law, which accounts $88.4 \%$ women have inadequate dietary calcium intake and also in Tigray the average mean intake of women of child bearing age was estimated $296.67 \pm 1.04 \mathrm{mg} /$ day, which is below the recommended EAR for women [7].

However, in poor counters availability and affordability of calcium are the main challenge to implement the recommendation $[2,4]$. Due to this other studies recommend that healthy dietary intake can meet micronutrient needs of pregnant women in developing countries [8,9]. Thus, this trail aimed to determine the effect of education on dietary calcium intake in decreasing variability of blood pressure in pregnant mothers.

\section{Methodology}

\section{Study Area, period and Trail design}

Single center, two-arm, main individual randomized trial parallel design, single blinded including 12-16 weeks follow up was conducted in selected district of Tigray Region from June to September 2019. Tigray is one of the 9 Regional states of Ethiopia and Mekelle is the capital city of the Region which is located $783 \mathrm{~km}$ North of Addis Ababa which is capital city of Ethiopia. Tigray Region, which has about one million hectares of arable land in total, is also successfully expanding its agriculture extension program. In Tigray, bread is one of the main foods. Two of the more common varieties are thin, pancakelike bread preferred by most people and a dense, disk-shaped loaf of baked whole wheat bread and is made from many kinds of cereal grains (wheat, barley, etc.). A variety of tsebhi (spicy stews) are eaten with the bread.

\section{Population}

All greater than 28 weeks gestational age pregnant mothers in Tigray region were the source population and all randomly selected pregnant mothers from the selected districts were study population.

\section{Eligibility criteria}

Pregnant women who had a mean systolic BP from 120 to $140 \mathrm{mmHg}$ and a diastolic BP from 80 to 90 $\mathrm{mmHg}$, based on six readings at two screening visits were included to the study and Mothers with a systolic BP $\geq 140 \mathrm{mmHg}$ or a diastolic BP $\geq 90 \mathrm{mmHg}$ or that were taking antihypertensive medications was excluded. In addition, persons with a self-reported history of clinical cardiovascular disease (CVD), cancer, chronic kidney disease, body mass index (BMI) $\geq 30 \mathrm{~kg} / \mathrm{m} 2$ were excluded from the study.

\section{Sample size determination}


The sample size for the study was calculated from a study which indicates maternal death due to hypertensive disorder was $20 \%$. Sample size was computed to detect minimum of $10 \%$ additional reduction in intervention as compared to the control arm with the following assumptions: level of significance $5 \%$; Power $80 \%$, lost to follow up $10 \%$. The required sample size was 415 subjects in all groups. The total duration of the intervention was 12-16 weeks.

\section{Trail intervention}

Dietary intake was assessed at baseline and in every weekly visit to household using an interactive 24hour recall method. After completing the baseline assessments (described further in study assessments) mothers were randomly assigned to either the education on dietary intake of calcium containing foods or the control group. The randomization was 1:1 for the 2 groups and was performed using simple randomization computer generated codes for each individual. For pregnant mothers in the calcium nutritional education intake group, a target calcium intake was calculated on the basis of 1200 milligram per day baseline, and the importance of meeting this target intake was explained to mothers. An estimate of current dietary intake was made from an interactive 24-h food recall; education was provided about the intake in relation to the target intake, and mothers were given a dietary plan to meet the target intake. Pregnant mothers were instructed to consume these foods per serving required to meet the target. Pregnant mothers were contacted house to house 3 times per week to assess progress and to provide the necessary feedback. Blood pressure was measured every month until the end of the intervention period. For pregnant mothers randomly assigned to the control group, general advice was given to address any major dietary imbalance identified from the interactive 24-h food recall at baseline. They were instructed to increase their food intake as they felt able but were not given a specific plan for dietary intake.

\section{Measurement of Blood Pressure}

Blood pressure was measured once per week per subject using an aneroid sphygmomanometer (Marshall Electronics, Inc., Clayton Division, Skokie, III.). Readings was recorded three times with 1 min between each reading. Participants was allowed a 10-min rest period before readings taken. All participants maintained a sitting position while blood pressure was measured in the non-dominant arm. A measurement was made at the same time of day by the same investigator, who was trained and experienced in the recording of blood pressure.

\section{Randomization and Blinding}

Each participating centre was assigned a special code generated by the computer using the simple randomization. The randomization was kept by the PI. The assessor for clinical outcomes was blinded to the randomization status. The research assistants who perform the intervention did not know the assessment result. After the eligibility assessment, blood pressure and dietary recall was conducted at the baseline (after completion of informed consent), at 4th, 8th and 12th weeks and every visit respectively. 


\section{Study outcome}

The primary outcome of interest was the BP variability between the study groups and Incidence of pregnancy induced hypertension were secondary outcome.

Explanatory variables: such as age, marital status, religion, educational level, occupation, monthly house hold income, family size, ANC visit, housing characteristics, household food insecurity, diversity of diet.

\section{Data collection procedures and quality Assurance}

The survey was community based structured and semi-structured, pre-tested, interviewer administered questionnaire mainly with closed ended questions was interviewed to pregnant mothers. The questionnaire was used to collect data through face-to-face interview on socio-demographic and dietary calcium intake. The questionnaires have adapted from different studies considering the local situation of the study area and contextualized to the study based on the relevant variables to be used. Data collectors provided a four days training on the data collection process. The research tool was first developed in English and then translated to the local language Tigrigna. The final version of the questionnaire was both in Tigrigna and English. Tigrigna version of the questionnaire was used for data collection to ensure clear understanding of the interviewee and respondents. To maintain quality and to estimate the time required collecting data, a pre-test was done on 21 individuals in nearby community to the intervention area to check the feasibility of the data collection process. Questionnaires were revised, as necessary, based on the pre-test and time required to fill one questionnaire was determined. During the study data collection, questionnaires were checked for its completeness and consistency by supervisors and principal investigators. Data that have entered in Epi data version 3.7 was checked for its accuracy by the principal investigators.

\section{Data management and analysis}

Blood pressure variability was compared between the intervention groups. Bi variable tabulations were computed to identify the distributions of the outcome variables by selected background characteristics. We estimated a multilevel model that assessed the relation of individual and community level factors (fixed effects) as well as community level random effects. Facility and community variables were considered as 'community level' variables in the study. Multilevel analysis was used to account for the hierarchical nature of the data. A two-level multilevel logistic regression model was estimated. The model consisted of two sub models at level 1 and level 2 (i.e., individuals (level 1) were nested within communities (level 2). A two-level multilevel model for a dichotomous outcome uses a binomial sampling and a logit link. We estimated four models. The first model was an empty model containing no covariates, but decomposed the total variance into individual and community components. The second model included individual characteristics. The third model contained only the community characteristics and this allowed the assessment of the relation of the community variables to the outcome variable. The final model contained explanatory variables at both the individual and community levels and allowed the assessment of the net effect of community variables over and above the individual variables. The 
variables were retained in each of the models if the variance component was significant $(p<0.05)$ or if they were important demographic variables. In all the estimated models, fixed effects were expressed as odds ratios (OR), while the random effects were expressed as variance partition coefficient (VPC) and proportional change in variance (PCV). Data was analysis using STATA 14.

\section{Ethical consideration}

Ethical clearance was obtained from Tigray health research institute, and an official support and permission letter was obtained from Tigray Regional Health Bureau. Written informed consent was assuring from the study participants, after explaining the purpose and significance of the study and they was assured that they had the right to withdraw from the study at any stage. Interview was conducted after receiving their consent. Confidentiality of the data/information was secured by assigning unique code to each of the participants and will not be used for other purpose.

\section{Result}

\section{Demographic and socio-economic characteristics}

A total of 415 early third trimester pregnant mothers were recruited. Of these, 203 were in the intervention group and another 212 in the control group with $100 \%$ response rate. The mean ages ( $\pm S D)$ of the mothers were $39( \pm 15)$ years. Out of the total mothers interviewed, three fourth $305(73.5 \%)$ belongs to the age group of 20-34 years. Most of the mothers 393(94.7\%) were currently in marital union and 395(95.2) them were orthodox religion believer. Six out of ten 254 (61.2\%) of the mothers were rural residence, greater than three-fourth of them had less 5 family members $320(77.1 \%)$. More than one third 320 $(41.9 \%)$ of the mothers and almost half of the husbands $196(47.2 \%)$ were illiterate. Majority of the maternal occupational 333(80.2\%) were housewife and more than half paternal occupation 234 (56.4\%) were farmers. One fifth of the mothers $86(20.72 \%)$ had middle wealth quintile [Table 1].

Table 1: Demographic and socio-economic characteristics of pregnant mother, Tigray Region, Northern Ethiopia, $2019(\mathrm{~N}=415)$ 


\begin{tabular}{|c|c|c|}
\hline Characteristics & Number & Percent \\
\hline \multicolumn{3}{|l|}{ Maternal Age } \\
\hline$<20$ years & 68 & 16.39 \\
\hline 20-34 years & 305 & 73.49 \\
\hline $35-49$ years & 42 & 10.12 \\
\hline \multicolumn{3}{|l|}{ Marital status } \\
\hline Marred & 393 & 94.70 \\
\hline Single & 15 & 3.61 \\
\hline Divorced & 7 & 1.69 \\
\hline \multicolumn{3}{|l|}{ Religion } \\
\hline Orthodox & 395 & 95.18 \\
\hline Muslim & 20 & 4.82 \\
\hline \multicolumn{3}{|l|}{ Place of Residence } \\
\hline Rural & 254 & 61.20 \\
\hline Urban & 161 & 38.80 \\
\hline \multicolumn{3}{|l|}{ Family members } \\
\hline$<5$ members & 320 & 77.11 \\
\hline$>5$ members & 95 & 22.89 \\
\hline \multicolumn{3}{|l|}{ Maternal highest Grade } \\
\hline No formal education & 174 & 41.93 \\
\hline Elementary School & 134 & 32.29 \\
\hline Above Secondary School & 107 & 25.8 \\
\hline \multicolumn{3}{|l|}{ Paternal highest grade } \\
\hline No formal education & 196 & 47.23 \\
\hline Elementary School completed & 107 & 25.78 \\
\hline Above secondary School & 112 & 27.0 \\
\hline \multicolumn{3}{|l|}{ Maternal occupation } \\
\hline Housewife & 333 & 80.24 \\
\hline Daily-laborer & 25 & 6.0 \\
\hline
\end{tabular}




\begin{tabular}{|lll|}
\hline Husband occupation & 57 & 13.7 \\
\hline Farmer & & \\
\hline Employed government & 56 & 13.49 \\
\hline Employed non-government & 25 & 6.0 \\
\hline Daily-laborer & 47 & 11.33 \\
\hline Self-employed non farming & 53 & 12.77 \\
\hline Wealth Quantiles & & \\
\hline Lowest & 82 & 19.76 \\
\hline Second & 84 & 20.24 \\
\hline Middle & 86 & 20.72 \\
\hline Fourth & 91 & 21.93 \\
\hline Highest & 72 & 17.35 \\
\hline
\end{tabular}

\section{Environmental characteristics}

Around four out of ten $182(43.9 \%)$ households did not possess toilet and out of the owners of toilet $112(48.1 \%)$ were pit latrine without slab [Table 2].

Table 2: Environmental characteristics of pregnant mothers, Tigray Region, Northern Ethiopia, 2019 $(\mathrm{N}=415)$ 


\begin{tabular}{|lll|}
\hline Characteristics & Number & Percent \\
\hline Have toilet & & \\
\hline Yes & 233 & 56.1 \\
\hline No & 182 & 43.9 \\
\hline Kind of toilet & & \\
\hline Pit latrine without slab & 112 & 48.1 \\
\hline Pit latrine with slab cover & 86 & 36.9 \\
\hline Ventilated improved pit latrine & 20 & 8.6 \\
\hline Flush toilet & 15 & 6.4 \\
\hline
\end{tabular}

\section{Obstetric and reproductive health characteristics}

Three-fourth 326 (78.5\%) of the mothers were willing to get pregnant and two third of the mothers 278 $(66.99 \%)$ were multi gravid and $150(36.1 \%)$ of them had $1-2$ parity. Majority of $409(98.5 \%)$ of mothers did not have history gestational diabetes, gestational hypertension or postpartum depression previously. Sixty one percent $(n=257)$ of mothers had received antenatal care during their last pregnancy. Around four percent ( $n=15), 246(59.3 \%)$ and $27(6.5 \%)$ were examined for ANC by Doctor/IEOS, Nurse/midwifery and Health extension workers respectively. Majority of the mothers $216(52 \%)$ receive ANC for their last delivery in public health centers. Ninety-five percent $(n=395)$ of the mothers receive ANC for their current pregnancy and $313(75.4 \%)$ of mothers receive ANC in public health center. Most of them $382(92 \%)$ took supplements (Iron/folic acid lodine, or other) during the current pregnancy [Table 3].

Table 3: Obstetric and reproductive health characteristics of pregnant mother, Tigray Region, Northern Ethiopia, $2019(\mathrm{~N}=415)$ 


\section{Characteristics}

When you got pregnant, did you want to get pregnant

Yes

No

\section{Gravidity}

Primi-gravida

Multi gravid

Parity

$1-2$

3-4

$>5$

Gestational diabetes, high blood pressure, depression, or postpartum depression in your last pregnancy

No history of the mentioned

History Gestational Diabetes

History of Gestational Hypertension

History postpartum depression

Receive antenatal care during you last pregnancy

Yes

No

\section{Examined by Doctor/IEOS during ANC}

Yes

No

Examined by Nurse/midwife during ANC

Yes

246

59.3

No

Examined by Health extension worker during ANC

Yes

6.5

$46 \quad 11.1$

Percent

78.55

21.45

33.01

66.99

19.8

11.1 


\begin{tabular}{|c|c|c|}
\hline No & 388 & 93.5 \\
\hline \multicolumn{3}{|c|}{ Receive antenatal care for your last child in Governmental Hospital } \\
\hline Yes & 15 & 3.6 \\
\hline No & 400 & 96.4 \\
\hline \multicolumn{3}{|c|}{ Receive antenatal care for your last child in public hospital } \\
\hline Yes & 84 & 20.2 \\
\hline No & 331 & 79.8 \\
\hline \multicolumn{3}{|c|}{ Receive antenatal care for your last child in public health center } \\
\hline Yes & 216 & 52.0 \\
\hline No & 199 & 48.0 \\
\hline \multicolumn{3}{|c|}{ Receive antenatal care for your last child in Health post } \\
\hline Yes & 23 & 5.5 \\
\hline No & 392 & 94.5 \\
\hline \multicolumn{3}{|c|}{ Did you see anyone for antenatal care for this pregnancy } \\
\hline Yes & 395 & 95.2 \\
\hline No & 20 & 4.8 \\
\hline \multicolumn{3}{|c|}{ Place receive antenatal care for current pregnancy } \\
\hline Government hospital & 30 & 7.2 \\
\hline Public hospital & 72 & 17.3 \\
\hline Public health center & 313 & 75.4 \\
\hline \multicolumn{3}{|c|}{ Did you take any supplements (Iron/folic acid lodine, or other) during this pregnancy } \\
\hline Yes & 382 & 92.0 \\
\hline No & 33 & 8.0 \\
\hline
\end{tabular}

\section{Dietary and nutritional characteristics}

Most of the pregnant mothers 392 (94\%) were supplemented iron folic acid less than 90 days. More than one third 138(33.3) of the household resources were managed by husband and $145(34.9 \%)$ of the participants feel little weight gain since they become pregnant. Around quarter 61(14.7) of the mothers 
were physically threatened by their husband and 34(8.2\%) of them felt down depressed or hopeless. Almost nine out of ten mothers $366(88.5 \%)$ had no food taboos during this pregnancy and $359(86.5 \%)$ of them had no food cravings during this pregnancy. Average calcium level at base line was mean ( \pm SD) $410 \pm 208$ gm [Table 4].

Table 4: Dietary and nutritional characteristics of pregnant mothers, Tigray Region, Northern Ethiopia, $2019(\mathrm{~N}=415)$ 


\begin{tabular}{|c|c|c|}
\hline Characteristics & Number & Percent \\
\hline \multicolumn{3}{|c|}{ Days Iron/folic acid supplemented } \\
\hline$<90$ days & 392 & 94 \\
\hline$>90$ days & 23 & 5.5 \\
\hline \multicolumn{3}{|c|}{ In the past month, have there been days when you did not have enough food or money to buy food } \\
\hline Yes & 81 & 19.5 \\
\hline No & 334 & 80.5 \\
\hline \multicolumn{3}{|c|}{ Household resources are managed by whom? } \\
\hline Partner & 138 & 33.3 \\
\hline Mother & 54 & 13.0 \\
\hline Both of them & 223 & 53.7 \\
\hline \multicolumn{3}{|c|}{ How do you feel about your weight change since you became pregnant? } \\
\hline Gaining too much & 95 & 22.9 \\
\hline Gaining too little & 145 & 34.9 \\
\hline It's okay & 116 & 28.0 \\
\hline Not sure & 37 & 8.9 \\
\hline Weight has not changed & 22 & 5.3 \\
\hline \multicolumn{3}{|c|}{ In the last month, has your partner physically threatened or tried to hurt you } \\
\hline Yes & 61 & 14.7 \\
\hline No & 354 & 85.3 \\
\hline \multicolumn{3}{|c|}{ In the last month, have you felt down, depressed, or hopeless } \\
\hline Yes & 34 & 8.2 \\
\hline No & 381 & 91.8 \\
\hline \multicolumn{3}{|c|}{ Any change in feeding habit } \\
\hline Yes & 64 & 15.4 \\
\hline No & 351 & 84.6 \\
\hline Food taboos during this & & \\
\hline
\end{tabular}




\begin{tabular}{|lll|}
\hline Yes & 49 & 11.8 \\
\hline No & 366 & 88.2 \\
\hline Yes & & \\
\hline No & 56 & 13.5 \\
\hline Food averted during this pregnancy & 359 & 86.5 \\
\hline Yes & & 13.0 \\
\hline No & 54 & 87.0 \\
\hline Average calcium intake & 361 & \\
\hline
\end{tabular}

Communication related characteristics

Majority of the mothers did not read a newspaper or magazine $275(66.3 \%)$ and More than half $249(59.8 \%)$ of the mothers did not listen radio and more than one third $284(68.4 \%)$ did not watch television [Table 5].

Table 5: Communication related characteristics of pregnant mothers, Tigray Region, Northern Ethiopia, 2019(N=415) 


\begin{tabular}{|lcc|}
\hline Characteristics & \multicolumn{1}{|c|}{ Number } & Percent \\
\hline \multicolumn{2}{|c|}{ Read a newspaper or magazine } \\
\hline At least once a week & 49 & 11.8 \\
\hline Less than once a week & 91 & 21.9 \\
\hline Not at all & 275 & 66.3 \\
\hline Do you listen Radio & & \\
\hline At least once a week & 102 & 24.6 \\
\hline Less than once a week & 65 & 15.7 \\
\hline Not at all & 248 & 59.8 \\
\hline Watch television & & \\
\hline At least once a week & 82 & 19.8 \\
\hline Less than once a week & 49 & 11.8 \\
\hline Not at all & 284 & 68.4 \\
\hline
\end{tabular}

\section{Factors affecting Blood pressure variability among groups}

Table 6 shows the results of mixed effect logistic regression analyses examining the effect of calcium nutrition education among pregnant women's individual characteristics and community-level factors in pregnant women in blood pressure fluctuation. Model 1, the empty model, includes only random intercept to capture between-cluster variability. In this model, $16 \%$ of the total variance in the odds of in blood pressure fluctuation was accounted for by between-cluster variation (ICC $=0.12$, The ICC was computed in each successive model to understand the relative effects of individual-level and community level factors on women in blood pressure fluctuation. Similarly, the ICC was computed in each successive model to understand the relative effects of individual-level and community level factors on calcium nutrition education to in blood pressure fluctuation. The between-cluster variability over successive models, from $12 \%$ in the empty model, to $9.7 \%$ in the individual-level only model, $8.9 \%$ in the community-level only model, and $8.3 \%$ in the combined model [Table 6]. Showing that variation in the blood pressure variability was explained best by the inclusion of both individual level characteristics.

The proportional of change in model in variance indicated the addition of predicators to the empty model better explained pregnant women calcium nutrition education change in blood pressure fluctuation.

\section{Individual level effect}


Model 2 contained only the individual level variables. Results showed that nutrition education on calcium for pregnant mothers was significantly associated with blood pressure variability, those mothers who got education had $62 \%$ lower blood pressure variability when compared with the control groups [AOR $=0.38$; $95 \% \mathrm{Cl}: 0.19,0.5]$. Concerning maternal highest grade, Pregnant mothers who attained secondary school had $79 \%$ less likely blood pressure variability than mothers who were with no formal education [AOR=0.21, 95\% Cl: $0.20,0.70$ ]. Employed pregnant women [AOR=9.05; 95\% $\mathrm{Cl}: 1.95,14.02$ ] had higher likelihood of blood pressure variability when compared to the reference category. Pregnant mothers who did not visit health facility for ANC had higher likely of blood pressure variability than those visited for ANC [AOR=1.82; $95 \% \mathrm{Cl}: 1.01,2.22]$. Women supplemented iron/folic acid less than 90 days had 6 times greater odds of blood pressure variability than women supplemented iron/folic greater than 90 days. Women who were not craving were $22 \%$ less likely blood pressure variability than those who were craving [AOR $=0.78 ; 95 \% \mathrm{Cl}: 0.20,0.98]$. The odds of blood pressure variability among women who read newspaper less than a week was $99.3 \%$ less likely than mother who did not read at all [AOR=9.05; $95 \% \mathrm{Cl}$ : $1.95,14.02]$. As the average calcium intake increased by 1 unit the blood pressure variability decreases by 0.99 unit [AOR $=-0.99 ; 95 \% \mathrm{Cl}: 0.993-0.998]$. Compared to the empty model, the variation in health facility delivery was significant across communities $(\tau=0.81, p<0.001)$. The intra-community correlation was $9.7 \%$ indicating the variability in the outcome variable.

\section{Community level effect}

We examined the effects of community level factors on the likelihood of blood pressure variability in model 3. As shown in the model, women living in urban area had 2.11 times higher odds of blood pressure variability than rural residents $[\mathrm{AOR}=2.11 ; 95 \% \mathrm{Cl}: 1.36,3.26]$. The intra individual correlation in the model increased, whereas that of the community decreased further suggesting that the proportional change in variance of odds of blood pressure across individuals and communities was explained by individual level characteristics. In other words this indicates that the differences in the likelihood of blood pressure variability were partly as a result of composition of communities by community level characteristics.

Finally we included both the individual and community variables in model 4 . For the individual level variables, the relationship was consistent with that observed in model 1. Nutrition education on calcium for pregnant mothers was significantly associated with blood pressure variability, those mothers who got education had $71 \%$ lower blood pressure variability when compared with the control groups [AOR $=0.29$; $95 \% \mathrm{Cl}: 0.19,0.50]$. Concerning maternal highest grade, Pregnant mothers who attained secondary school had $80 \%$ less likely blood pressure variability than mothers who were with no formal education [AOR $=0.20,95 \% \mathrm{Cl}: 0.04,0.97$ ]. Employed pregnant women [AOR=10.17; $95 \% \mathrm{Cl}: 1.96,15.28$ ] had 9 times higher likelihood of blood pressure variability when compared to the reference category. Pregnant mothers who did not visit health facility for ANC had 1.4 times higher likely of blood pressure variability than those visited for ANC [AOR=1.39; $95 \% \mathrm{Cl}: 1.05,1.83]$. Women supplemented iron/folic acid less than 90 days had 6 times greater odds of blood pressure variability than women supplemented iron/folic greater than 90 days. Women who were not craving were $23 \%$ less likely blood pressure variability than 
those who were craving [AOR=0.77; $95 \% \mathrm{Cl}: 0.18,0.0 .93]$. The odds of blood pressure variability among women who read newspaper less than a week was $99.3 \%$ less likely than mother who did not read at all [AOR $=0.07 ; 95 \% \mathrm{Cl}: 0.01,0.40]$. As the average calcium intake increased by 1 unit the blood pressure variability decreases by 0.99 units [AOR $=-0.99 ; 95 \% \mathrm{Cl}$ : 0.993-0.998]. However there are no significant community factors on the combined model 4 . The community level variance was significant $(\tau=0.12$, $p<0.001)$. The intra-community correlation decreased to $8.3 \%$ suggesting that the inclusion of the community variables improved the overall explained variance in the use of delivery care compared with model 3. Moreover, the smaller values of AIC and BIC indicated that model 4 was a better explanatory model.

Table 6: Two level mixed effect logistic regression of individual and community factors on Blood Pressure variability during pregnancy, Tigray Region, 2019 


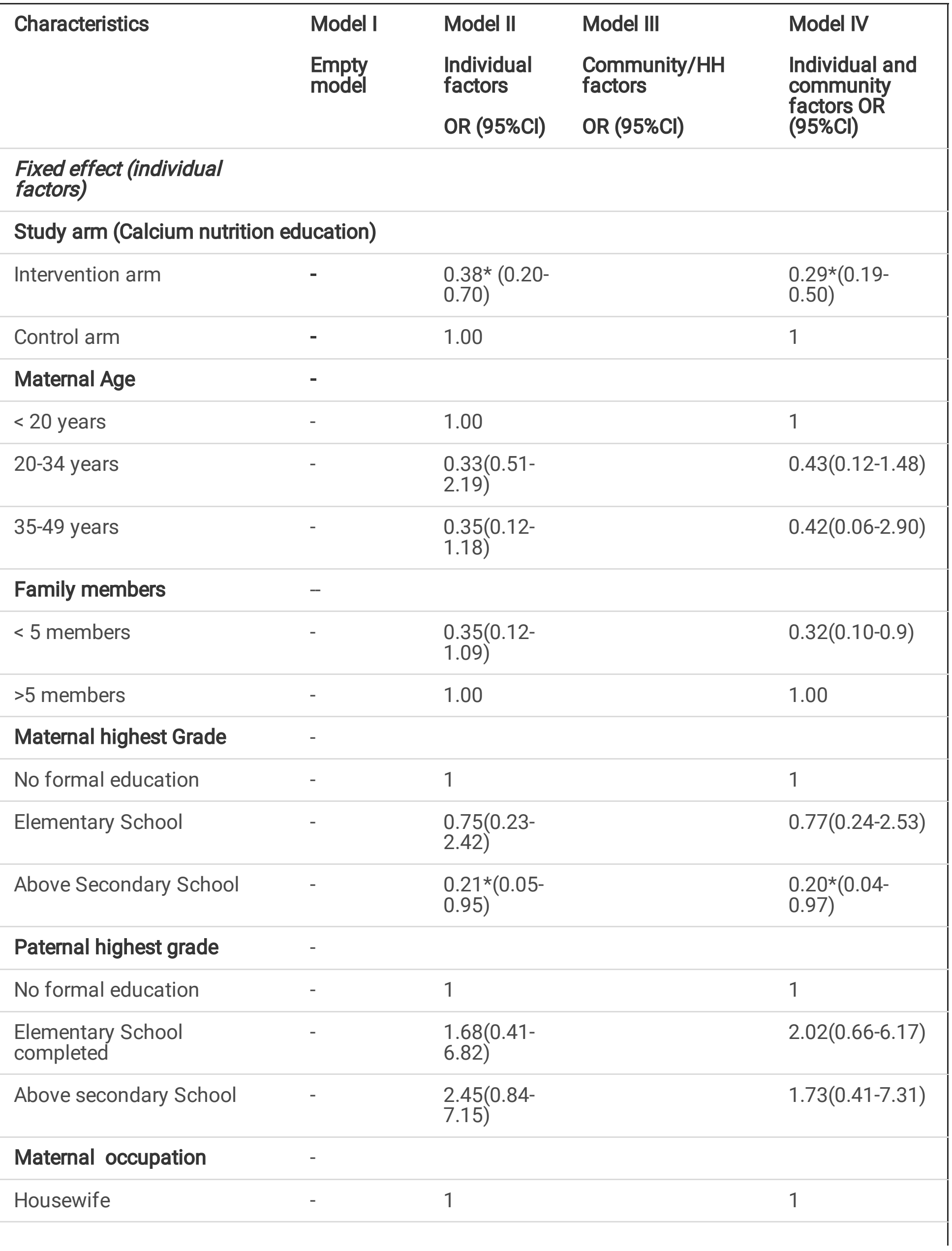




\begin{tabular}{|c|c|c|c|}
\hline Daily-laborer & - & $\begin{array}{l}0.35(0.06- \\
1.96)\end{array}$ & \\
\hline Employed & - & $\begin{array}{l}9.05 *(1.95- \\
14.02)\end{array}$ & $\begin{array}{l}10.17 *(1.96- \\
15.28)\end{array}$ \\
\hline Husband occupation & - & & \\
\hline Farmer & - & 1 & 1 \\
\hline Employed government & - & $\begin{array}{l}1.06(0.20- \\
5.56)\end{array}$ & $0.90(0.16-5.20)$ \\
\hline Employed non-government & - & $\begin{array}{l}1.67(0.32- \\
8.79)\end{array}$ & 1.52(0.27-8.57) \\
\hline Daily-laborer & - & $\begin{array}{l}2.01(0.41- \\
9.86)\end{array}$ & $1.8900 .36-9.82$ \\
\hline Self-employed non farming & - & $\begin{array}{l}1.55(0.38- \\
6.18)\end{array}$ & $1.38(0.31-6.15)$ \\
\hline Wealth Quantilles & - & & \\
\hline Lowest & - & 1 & 1 \\
\hline Second & - & $\begin{array}{l}1.44(0.41- \\
5.12)\end{array}$ & $1.38(0.38-5.04)$ \\
\hline Middle & - & $\begin{array}{l}2.01(0.41- \\
9.78)\end{array}$ & $\begin{array}{l}1.93(0.36- \\
10.24)\end{array}$ \\
\hline Fourth & - & $\begin{array}{l}0.27(0.06- \\
1.26)\end{array}$ & $0.27(0.06-1.27)$ \\
\hline Highest & - & $\begin{array}{l}0.86(0.17- \\
4.35)\end{array}$ & $0.98(0.18-5.44)$ \\
\hline Have toilet & - & & \\
\hline Yes & - & 1 & 1 \\
\hline No & - & $\begin{array}{l}0.59(0.23- \\
1.52)\end{array}$ & $0.63(0.23-1.69)$ \\
\hline \multicolumn{4}{|c|}{ When you got pregnant, did you want to get pregnant } \\
\hline Yes & - & 1.00 & 1 \\
\hline No & - & $\begin{array}{l}1.36(0.45- \\
4.13)\end{array}$ & $1.56(0.49-4.94)$ \\
\hline Gravidity & - & & \\
\hline Primi gravid & - & 1.00 & 1 \\
\hline Multi gravid & - & $\begin{array}{l}0.65(0.24- \\
1.73)\end{array}$ & $0.67(0.25-1.82)$ \\
\hline
\end{tabular}


Receive antenatal care during you last pregnancy

Yes

1

1

No

$1.82 *(1.01-$

2.22)

$1.39 *(1.05-$

1.83)

Did you see anyone for antenatal care for this pregnancy

$\begin{array}{llll}\text { Yes } & - & 1.00 & 1 \\ \text { No } & - & 1.65^{*}(1.24- & 1.78^{\star}(0.33- \\ & & 1.73) & 0.99)\end{array}$

Place receive antenatal care for current pregnancy

Government hospital 1

1

Public hospital

$6.51(057-$

73.97)

2.26(0.16-

30.93)

Public health center

$2.09(0.17-$

25.98)

8.66(0.57-

13.10)

Did you take any supplements (Iron/folic acid lodine, or other) during this pregnancy

\begin{tabular}{|c|c|c|}
\hline Yes & - & 1 \\
\hline No & $\begin{array}{l}2.16(0.52- \\
8.97)\end{array}$ & $1.69(0.39-7.33)$ \\
\hline
\end{tabular}

Days Iron/folic acid

supplemented

$\begin{array}{llll}>90 \text { days } & - & 1 & 1 \\ <90 \text { days } & - & 6.32 *(1.09- & 7.88^{*}(1.29-\end{array}$

In the past month, have there been days when you did not have enough food or money to buy food

\begin{tabular}{|c|c|c|}
\hline Yes & - & 1 \\
\hline No & $\begin{array}{l}0.67(0.25- \\
1.86)\end{array}$ & $0.61(0.21-1.76)$ \\
\hline
\end{tabular}

Household resources are managed

$\begin{array}{llll}\text { Partner } & - & 1 & 1 \\ \text { Mother } & - & 0.77(0.20- & 0.94(0.22-3.98) \\ & & 2.99) & 1.37(1.08-3.86) \\ \text { Both of them } & - & 1.21(0.44- & \end{array}$

How do you feel about your weight change since you became pregnant 


\begin{tabular}{|c|c|c|c|}
\hline Gaining too much & - & 1 & 1 \\
\hline Gaining too little & - & $\begin{array}{l}0.87(0.29- \\
2.60)\end{array}$ & $0.89(0.29-2.71)$ \\
\hline It's okay & - & $\begin{array}{l}0.57(0.16- \\
2.06)\end{array}$ & $0.62(0.16-2.38)$ \\
\hline Not sure & - & $\begin{array}{l}0.19(0.02- \\
1.73)\end{array}$ & $0.15(0.01-1.65)$ \\
\hline Weight has not changed & - & $\begin{array}{l}3.96(0.64- \\
24.43)\end{array}$ & $\begin{array}{l}3.39(0.49- \\
23.67)\end{array}$ \\
\hline \multicolumn{4}{|c|}{ In the last month, has your partner physically threatened or tried to hurt you } \\
\hline Yes & - & 1 & 1 \\
\hline No & - & $\begin{array}{l}0.63(0.11- \\
3.52)\end{array}$ & $0.88(0.14-5.40)$ \\
\hline \multicolumn{4}{|c|}{ In the last month, have you felt down, depressed, or hopeless } \\
\hline Yes & - & 1 & 1 \\
\hline No & - & $\begin{array}{l}0.81(0.07- \\
9.36)\end{array}$ & $0.67(0.05-8.45)$ \\
\hline \multicolumn{4}{|c|}{ Any change in feeding habit } \\
\hline Yes & - & 1 & 1 \\
\hline No & - & $\begin{array}{l}1.25(0.35- \\
4.50)\end{array}$ & $1.27(0.34-4.75)$ \\
\hline \multicolumn{4}{|l|}{$\begin{array}{l}\text { Food taboos during this } \\
\text { pregnancy }\end{array}$} \\
\hline Yes & - & 1 & 1 \\
\hline No & - & $\begin{array}{l}0.86(0.21- \\
3.59)\end{array}$ & $0.96(0.22-4.26)$ \\
\hline \multicolumn{4}{|l|}{$\begin{array}{l}\text { Food cravings during this } \\
\text { pregnancy }\end{array}$} \\
\hline Yes & - & 1 & 1 \\
\hline No & - & $\begin{array}{l}0.78^{\star}(0.20- \\
0.98)\end{array}$ & $\begin{array}{l}0.77 *(0.18- \\
0.93)\end{array}$ \\
\hline \multicolumn{4}{|l|}{$\begin{array}{l}\text { Food averted during this } \\
\text { pregnancy }\end{array}$} \\
\hline Yes & - & 1 & 1 \\
\hline No & - & $\begin{array}{l}3.45(0.88- \\
13.57)\end{array}$ & $\begin{array}{l}3.27(0.78- \\
13.59)\end{array}$ \\
\hline
\end{tabular}



Average calcium intake
$0.996 *$
$0.996 *(0.993-$
(0.993-
0.998)
$0.998)$

\section{Read a newspaper or magazine}

\begin{tabular}{llll} 
Not at all & - & 1 & 1 \\
\hline Less than once a week & - & $0.07 *(0.01-$ & $0.07 *(0.01-$ \\
& & $0.43)$ & $0.40)$ \\
\hline At least once a week & - & $0.35(0.09-$ & $0.29(0.07-1.28)$ \\
\hline Do you listen radio & & $1.40)$ & \\
\hline Not at all & - & 1 & 1 \\
\hline Less than once a week & - & $0.86(0.20-$ & $1.03(0.23-4.56)$ \\
\hline At least once a week & - & $0.68)$ & $0.86(0.26-2.82)$ \\
\hline Watch television & & $2.48)$ & \\
\hline Not at all & - & 1 & 1 \\
\hline Less than once a week & - & $0.64(0.10-$ & $0.55(0.08-3.58)$ \\
\hline At least once a week & - & $3.96)$ & $0.99(0.22-4.53)$ \\
\hline
\end{tabular}

Fixed effect (Community/facility factors)

Place of Residence

Rural

$-$

1

1

Urban

$2.11 *(1.36-3.26)$

$1.39(0.44-4.44)$

\section{Examined by Doctor/IEOS} during ANC

Yes
No
Examined by Nurse/midwife
during ANC

Yes

No
1

1.09(0.71-1.67)
1

2.96(0.4917.80) 
extension worker during ANC

\begin{tabular}{|c|c|c|c|c|}
\hline Yes & - & & 1 & 1 \\
\hline No & - & & $0.71(0.29-1.72)$ & $0.63(0.08-4.69)$ \\
\hline Random effects & Empty & Individual & Community/facility & $\begin{array}{l}\text { Individual and } \\
\text { community }\end{array}$ \\
\hline Variance (SE) & $\begin{array}{l}0.16^{\star} \\
(0.609)\end{array}$ & $0.81 *(0.5)$ & $0.36 *(0.07)$ & $0.12 *(0.53)$ \\
\hline$(\mathrm{VPC})=\operatorname{ICC}(\%)$ & $12 \%$ & $9.7 \%$ & $8.9 \%$ & $8.3 \%$ \\
\hline PCV & Reference & 35 & 22 & 12 \\
\hline Log-likelihood & -276.68484 & -117.81133 & -269.68537 & -116.30423 \\
\hline \multicolumn{5}{|c|}{ Model fit statistics } \\
\hline AIC & 557.3697 & 291.6227 & 551.3707 & 296.6085 \\
\hline $\mathrm{BIC}$ & 565.4262 & 384.2542 & 575.5404 & 402.473 \\
\hline
\end{tabular}

$N B$ : * indicates significant variable in its respective model, the empty model contains no variables, $S E=$ Standard error, VPC= Partition variance coefficient $A I C=A$ kaike Information Criteria. $P C V$ was calculated for successive models with reference to null model to look at relative contribution of each model to explain BP variability

\section{Discussion}

The primary objective of this research was to examine the effect of calcium nutrition education on blood pressure variability among pregnant mothers, and accordingly pregnant mother who got nutrition calcium education had decreased blood pressure variability. And other significant factors that affect blood pressure variability among pregnant mothers were individual level factors (maternal educational status, maternal occupation, ANC during their last and current pregnancy, iron/folic acid supplementation, food craving, calcium intake and reading news paper) and community factors (place of residence).

Calcium nutrition education showed significant association with blood pressure variability among pregnant mothers. This result indicates that mothers who had knowledge regarding what to feed that have effect on blood pressure variability had less likely of blood pressure variability. A study done in Ethiopia in support of this showed that pregnant mothers who has no awareness on risk hypertension were more likely develop PIH as compared to their counter parts [10]. This result indicates that if pregnant mother are educated regarding calcium nutrition from previous evidence which has been proposed that low-calcium intake may increase blood pressure by stimulating either parathyroid hormone or renin release, increasing intracellular calcium in vascular smooth muscle and leading to vasoconstriction. Calcium supplementation may reduce parathyroid release and could reduce smooth muscle contractility. It could also reduce uterine smooth muscle contractility or increase serum magnesium levels and thus 
prevent preterm labour and delivery [11]. And also other meta-analysis result conducted in United Kingdom showed that among interventions, those based mainly on diet showed a significant reduction in pre-eclampsia by $33 \%$, compared with the controls [12].

Other finding were maternal education has significant association with blood pressure variability specifically educated pregnant mothers had lower blood pressure variability. This result is similar with study done in Netherland that showed that women with relatively low levels of education had a higher risk of gestational hypertension than women with a high level [13]. This implies that if we educate mothers on nutrition there might decrease pregnancy induced hypertension.

The study revealed that maternal occupation was significantly affecting blood pressure variability among pregnant mothers. Previous studies have found mixed outcomes. This study was in line with study done in Bangladesh [14]. However this finding was inconsistent with study done in Taiwan [15]. Employed pregnant mothers are at risk of blood pressure variability this could be due to one of the suggested mechanism through which physically demanding work and psychological stress could lead to hypertensive disorders during pregnancy is an increased utero placental vascular resistance which follows physical exertion. Physically demanding work may cause an increase in catecholamine levels, which may lead to a decreased uterine blood flow and therefore may induce PIH and preeclampsia. It has also been suggested that part of the excess catecholamine release is due to an overactive sympathetic nervous system[16]. Whatever this could support the finding; however, further research is warranted to confirm these negative findings.

Another significant predictor for blood pressure variability was Antenatal care follow-up during the last pregnancy and current pregnancy. Antenatal care (ANC) is a care of women during pregnancy by skilled health care providers. The components of ANC include: early high risk screening, prevention and care of pregnancy-related complications, including $\mathrm{PIH}$, and provision of health education and health promotion. With adequate ANC ( $\geq 4$ times), pregnant women would be monitored and have better pregnancy outcomes and a reduction in complications. This study is supported by study done in Thailand [17], USA [18]. Pregnancy induced hypertension is not a totally preventable disease but maternal and foetal Complication due to PIH can be halted at mild stage by quality Antenatal care with good outcome through controlling blood pressure variability.

The other main exposure variable used in our study was self-reported consumption of iron and folic acid supplementation during pregnancy. Iron/folic supplementation had significant association with blood pressure variability among pregnant mothers. This finding is consistent with the study done in India which indicates the likelihood of reporting Preeclampsia or eclampsia symptoms was lower among those mothers who consumed iron and folic acid supplementation for at least 90 days during their last pregnancy [19]. Iron plays a significant role inter alia in: Oxygen transport, in the production of ATP, in the synthesis of DNA, in preserving the function of mitochondria and in protecting cell structures against oxidative damage, in the activity of numerous enzymes, as well as in cell growth and proliferation. Iron plays a catalyzing role in the production of reactive oxygen species in the Fenton and Haber-Weiss 
reactions. The role of iron in the development of the placenta is not fully understood, but the discovery of the hypoxia-inducible factor (HIF) and its regulatory mechanisms also drew attention to the importance of iron. Another systematic review and Meta analysis done in china showed that iron deficiency correlates with some complications of pregnancy [20].

Food craving was another predictor for blood pressure variability at individual level. This was consistent with study done in Ghana which revealed that specifically geophagia was associated with pregnancy diastolic blood pressure variability [21]. Cravings in women have been shown to increase in frequency and intensity at two distinct times: during the perimenstrum (i.e., a period of about eight days around the onset of menstruation) and in pregnancy [22].

Dietary calcium intake was one of the significant factors associated with blood pressure variability. Low calcium intake has been hypothesized to cause increase in blood pressure by stimulating the release of parathyroid hormone and/or renin which leads to increased intracellular calcium concentration in vascular smooth muscle cells and causes vasoconstriction. Whatever different research finding $[23,24]$ showed that calcium supplementation had significant effect on decreasing blood pressure variability and also this study indicates that if we educate mother on calcium nutrition there might be increase consumption of calcium so might lead to decreased blood pressure variability.

The other significant factor was reading newspaper, this might be due to if pregnant mother are reading newspaper they could get information concerning their pregnancy nutrition then after they may have knowledge what feed and regarding the complication during pregnancy. Health literacy is the degree to which individuals have the capacity to obtain, process, and understand basic health information and services needed to make appropriate health decisions. It comprises a complex set of reading, listening, analytical, decision-making skills, and the ability to apply these skills to health problems. Low health literacy during the perinatal period, and specifically about preeclampsia, may contribute not only to women's poor understanding of pregnancy and potential fetal health issues, but also to delayed care and poor health outcomes.

Regarding the community level factors place of residence was one of the significant factors affecting blood pressure variability. Urban residents were at risk of blood pressure variability. However a study done in Ethiopia, tigray showed that rural residents were at greater odds of suffering from hypertensive disorders [25]. The difference could be due to the study design used because they are different.

\section{Conclusion}

Individual level factors were significantly associated with blood pressure variability. Individual level factors (Calcium nutrition education, maternal educational status, maternal occupation, Antenatal care during last pregnancy and current pregnancy, iron/folic acid supplementation, food craving, dietary calcium level and reading newspaper) and community level factors (place of residence) were significant predictors of blood pressure variability among pregnant mother after 28 gestational age. During antenatal visits, pregnant women should be made aware of some dietary practices which are harmful 
during pregnancy, and increase education regarding the benefit of adequate nutrition. Nutrient supplementation should be administered to pregnant women, especially those living in low socioeconomic areas to supplement dietary intakes. A prospective cohort study should have to be conducted using blood biomarkers of nutrients to properly determine the role of nutrients in the development of hypertension in pregnancy. Calcium nutrition education should have to be given through the health extension workers after developing guideline and Regional food composition table on how to counsel, type of foods found in tigray which have high calcium content.

\section{List Of Abbreviations}

$\begin{array}{ll}\text { ANC } & \text { Antenatal Care } \\ \text { BMI } & \text { Body Mass Index } \\ \text { Bp } & \text { Blood pressure } \\ \text { CVD } & \text { Cardio Vascular disease }\end{array}$

\section{Declarations}

\section{Ethics approval and consent to participate}

Participation was voluntary for all participants. Before the interview, the interviewer explained in detail the content of the questionnaire, informed the participants on confidentiality of their responses and of their free choice to withdraw from the study during the interview or later. A written consent was obtained from all participants. The study was approved by the Institutional Review Board of the Tigray Health Research Institute (No: IRB145/2019).

\section{Consent for publication}

Not applicable

\section{Availability data and material}

The datasets used and/or analyzed during the current study is available from the corresponding author on request.

\section{Competing interest}

The authors' declare that they have no conflict of interest.

\section{Funding}

This research is not funded by any organization 


\section{Author Contributions}

Conceptualization: Mulugeta Woldu, Alemnesh Abrha.

Formal analysis: Alemnesh Abrha, Ataklty Gebretsadik, Brhane Ayele, Equbay Gebreegziabher

Methodology: Afework Mulugeta, Haylay Gebretnsae,Tsegay Hadgu

Validation: Afework Mulugeta, Brhane Ayele

Writing - original draft: Mulugeta Woldu,Alemnesh Abrha, Ataklty Gebretsadik

Writing - review \& editing: Brhane Ayele, Haylay Gebretensae, Equbay Gebre-egziabher, Tsegay Hadgu, Afework Mulugeta. All authors have read and approved the manuscript

\section{Acknowledgment}

Our heartfelt thanks go to the Tigray Health Research Institute for allowing us to undergoing this research.

\section{References}

1. Nutrient reference values for Australia and New Zealand. (2014). Retrieved from https://ascensionkitchen.com/calcium-on-a-plant-based-diet/.

2. WHO

WHO. Guideline: Calcium supplementation in pregnant women. Geneva, World Health Organization, 2013.

3. Chotboon C, Soontrapa S, Buppasiri P, et al. Adequacy of calcium intake during pregnancy in a tertiary care center. International Journal of Women's Health 2018:10 523-527.

4. Van Mierlo LA, Arends LR, Streppel MT, Zeegers MP, Kok FJ, Grobbee DE, Geleijnse JM. Blood pressure response to calcium supplementation: a meta-analysis of randomized controlled trials. $\mathrm{J}$ Hum Hypertens. 2006;20:571-80. doi:10.1038/sj.jhh.1002038.

5. Getinet Ayele S. Factors Associated with Hypertension during Pregnancy in Derashie Woreda South Ethiopia, Case Control. Qual Prim Care. 2016.

6. Sammya Bezerra Maia e Holanda Moura Sammya Bezerra Maia e Holanda Moura. Lopes LM, Murthi P, Costa FS, "Prevention of Preeclampsia," Journal of Pregnancy, vol. 2012, Article ID 435090, 9 pages, 2012.

7. Tesfaye B, Wuehler S, Moges T, Samuel A, Kebede A, Zerfu A, Abera A, Mengistu G, Wodajo G, Katherine A, Jalal C, Kebede A. Making a Case for Calcium Supplementation for Prevention of Pregnancy Hypertension in Ethiopia. European Journal of Nutrition Food Safety. 2015;5(5):1187-8. Article no.EJNFS.2015.502 www.sciencedomain.org. 
8. Schoenaker DAJM, Soedamah-Muthu SS, Mishra GD. The association between dietary factors and gestational hypertension and pre-eclampsia: a systematic review and meta-analysis of observational studies. BMC Med [Internet]. 2014 Sep;22:12:157.

9. Ndanuko RN, Tapsell LC, Charlton KE, Neale EP, Batterham MJ. Dietary Patterns and Blood Pressure in Adults: A Systematic Review and Meta-Analysis of Randomized Controlled Trials. Adv Nutr. 2016;7(1):76-89.

10. Getinet Ayele S. Factors Associated with Hypertension during Pregnancy in Derashie Woreda South Ethiopia, Case Control. Qual Prim Care. 2016;24:207-13.

11. Bezerra Maia e Holanda. Moura S, Marques Lopes L, Murthi P. Da Silva Costa F. Prevention of preeclampsia. J Pregnancy. 2012;2012.

12. Allen R, Rogozinska E, Sivarajasingam P, Khan KS, Thangaratinam S. Effect of diet- And lifestylebased metabolic risk-modifying interventions on preeclampsia: A meta-analysis. Acta Obstet Gynecol Scand. 2014;93(10):973-85.

13. Silva L, Coolman $M$, Steegers $E$, et al. Maternal educational level and risk of gestational hypertension: the Generation R Study. J Hum Hypertens. 2008;22(7):483-92. doi:10.1038/jhh.2008.22.

14. Sultana N. Pregnancy Induced Hypertension and Associated Factors among Pregnant Women. J Gynecol Womens Heal. 2017;3(5).

15. Chang PJ, Chu LC, Hsieh WS, Chuang YL, Lin SJ, Chen PC. Working hours and risk of gestational hypertension and pre-eclampsia. Occup Med (Chic III). 2009;60(1):66-71.

16. Nugteren JJ, Snijder CA, Hofman A, Jaddoe VWV, Steegers EAP, et al. Work-Related Maternal Risk Factors and the Risk of Pregnancy Induced Hypertension and Preeclampsia during Pregnancy. The Generation R Study. PLoS ONE. 2012;7(6):e39263. doi:10.1371/journal.pone.0039263.

17. Phengsavanh A, Laohasiriwong W, Suwannaphant K, Assana S, Phajan T, Chaleunvong K. Antenatal care and its effect on risk of pregnancy induced hypertension in lao pdr: A case-control study [version 1; peer review: 1 approved, 1 approved with reservations]. F1000Research. 2018;7(May):1-11.

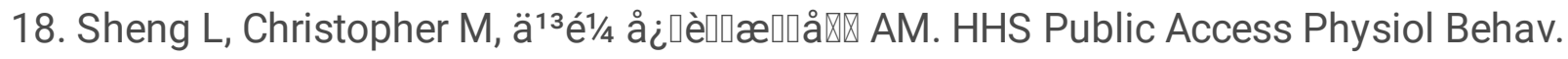
2016;176(1):100-6.

19. Agrawal S, Fledderjohann J, Vellakkal S, Stuckler D. Adequately diversified dietary intake and iron and folic acid supplementation during pregnancy is associated with reduced occurrence of symptoms suggestive of pre-eclampsia or eclampsia in indian women. PLoS One. 2015;10(3):1-23.

20. Fu APA, Shimin MM, Li FMM, Zhou, Jianguo MM, Liu. Zhiping The Relationship Between Body Iron Status, Iron Intake And Gestational Diabetes, Medicine: January 2016 - Volume 95 - Issue 2 - p e2383 doi: 10.1097/MD.0000000000002383.

21. Sackey DS, Larbie C, Mensah FO. Geophagia, nutrition and health of women with pregnancy-induced hypertension. Afr Health Sci. 2018;18(4):1243-54.

22. Orloff NC, Hormes JM. Pickles and ice cream! Food cravings in pregnancy: hypotheses, preliminary evidence, and directions for future research [Internet]. Vol. 5, Frontiers in Psychology. 2014. p. 1076. 
23. Imdad A, Jabeen A, Bhutta ZA. Role of calcium supplementation during pregnancy in reducing risk of developing gestational hypertensive disorders: a meta-analysis of studies from developing countries. BMC Public Health. 2011;11:18. https://doi.org/10.1186/1471-2458-11-S3-S18.

24. Lorrene D, Ritchie JC, King. Dietary calcium and pregnancy-induced hypertension: is there a relation?, The American Journal of Clinical Nutrition, Volume 71, Issue 5, May 2000, Pages 1371S-1374S, https://doi.org/10.1093/ajcn/71.5.1371s.

25. Kahsay HB, Gashe FE, Ayele WM. Risk factors for hypertensive disorders of pregnancy among mothers in Tigray region, Ethiopia: matched case-control study. BMC Pregnancy Childbirth. 2018;18(1):482. doi:10.1186/s12884-018-2106-5. Published 2018 Dec 6.

\section{Figures}

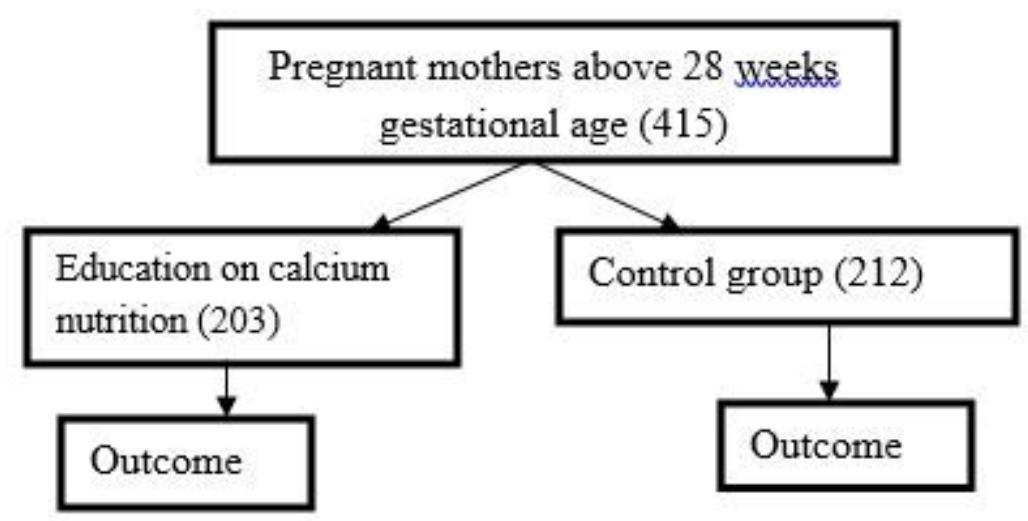

Figure 1

Schematic representation of randomization of pregnant mothers 